\title{
Country Roads Through 1s and 0s: Sense of Place for and Recollection of West Virginia Following Long-Term Engagement With Fallout 76
}

\author{
Nicholas D. Bowman ${ }^{1}$, Jaime Banks ${ }^{1}$, and Christine E. Rittenour ${ }^{2}$ \\ ${ }^{1}$ College of Media and Communication, Texas Tech University \\ ${ }^{2}$ Department of Communication Studies, West Virginia University
}

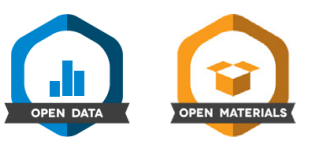

Invoking Tuan's cultural-geographic notion of sense of place (SoP), this study examined the potential for video game play to foster a sense of affective familiarity with (emotional connection) and abstract understanding of (place recollection) actual physical locations rendered in digital environments. A total of 556 players of Fallout 76 were asked about their SoP for and recollection of West Virginia (WV) 2 weeks prior to the game's launch (T1), with follow-up questions 2 weeks (T2) and 2 months (T3) following the game's launch. SoP scores were compared between WV natives and non-natives, with the expectation that natives would have greater SoP scores prior to gameplay. The expected T1 SoP gap was found, but this gap closed for all players at T2, with non-natives experiencing a significant increase in their SoP for WV on par with natives' feelings of the same. For those no longer playing, T3 SoP scores returned to T1 (preplay) levels. Effects on place recollection (such as recalling location names) were similar but less pronounced. Although an early exploration into SoP and video games, these data have implications for SoP considerations in video game research and design.

Keywords: sense of place, video games, Fallout 76, longitudinal design

Supplemental materials: https://doi.org/10.1037/tmb0000001\#supplemental-materials

Video games are lauded for their ability to transport people into unreal scenarios and to help players to escape into fantasy narratives and unattainable locales. Part of this potential relies on dynamics such as spatial presence and interactivity that create a sense of being there - an illusion of nonmediation such that the digital world is

Action Editor: Danielle S. McNamara served as the action editor for this article.

ORCID iDs: Nicholas D. Bowman (iD https://orcid.org/0000-0001-55949713; Jaime Banks (D) https://orcid.org/0000-0002-7598-4337.

Open Science Disclosures:

In The data are available at https://osf.io/n9dw5/.

- The experiment materials are available at https://osf.io/n9dw5/.

Disclosure and Acknowledgment: We have no conflicts of interest with this research. We would like to thank Lindsey Resignato for her editorial assistance with the final production of this manuscript.

Open Access License: This work is licensed under a Creative Commons Attribution-NonCommercial-NoDerivatives 4.0 International License (CC-BYNC-ND). This license permits copying and redistributing the work in any medium or format for noncommercial use provided the original authors and source are credited and a link to the license is included in attribution. No derivative works are permitted under this license.

Disclaimer: Interactive content is included in the online version of this article.

Contact Information: Correspondence concerning this article should be addressed to Nicholas D. Bowman, 512 CoMC, College of Media and Communication, Texas Tech University, Lubbock, TX 79410, United States. Email: nick.bowman@ttu.edu experienced as an actual location (Lombard \& Ditton, 1997). However, games are increasingly set in very real locales, sometimes with very high fidelity to their physical-world counterparts, and designed to closely replicate and simulate these locales (e.g., the 2019 release of The Division 2 includes a nearly 1:1 scale representation of Washington, DC; Ubisoft, 2019). So what, then, of the potential for digital game environments to engender a sense of place (SoP), a concept borrowed from cultural geography to explain the idiosyncratic and emotional connection between people and places (Tuan, 1974, 1975, 1979) that goes beyond simply recognizing labels or names or locations and beyond senses of being there (i.e., spatial presence), but emerges as a "perception of meaning associated with a site or location" (Bott, 2000, p. 7)?

The current study examines some of this potential by examining players' experiences in the video game Fallout 76, a game that attempted to move beyond simply recognizing labels or names or locations in West Virginia (WV) and immerse players in a postapocalyptic Appalachian world based on current-day places and cultural pathos of the same. By following players 2 weeks prior to play, 2 weeks after initial play, and 2 months after initial play, we are able to track the development of both (a) players' perceptions of SoP in WV and (b) players' recollection of various locations around WV, with consideration for preexisting affiliations with the state. Findings suggest that native West Virginians have a stronger SoP than nonnatives prior to the game's release, but the two groups' SoP and location recall for WV (as an actual space) converged over the course of gameplay, providing theoretical and empirical grounding for the study of SoP in video games. 


\section{Review of Literature}

\section{SoP}

The notion of an SoP can be traced back to canonical scholarship in cultural geography by Tuan $(1975,1979)$. In his earliest work (1975), Tuan argues that when we visit places, there is an experience that transcends the labels formally given to the spaces that are being occupied. Summarized, "to know a place fully means both to understand it in an abstract way and to know it as one person knows another" (Tuan, 1975, p. 152). In this quote, the abstract refers to the historical facts, labels, and other observable and quantifiable features of a place. Although these abstract facts can be learned by an observer, they cannot be directly experienced and, thus, do not contribute to an SoP for the observer. For example, a city by name can be quite old chronologically: The city of Indianapolis was founded after the signing of the Treaty of St. Mary's in 1818 between the newly formed state of Indiana and the Delaware indigenous tribe to allow the former to establish a central seat of governance on the latter's tribal lands (the city, of course, having a much older cultural and social history extending beyond contemporary U.S. history). Rather, human experiences inherent to that place are better understood as idiosyncratic experience goods (Nelson, 1970)_in a sense, different people will hold slightly different mental models (internalized versions of the place; see Valiquette \& McNamara, 2007). They can only be understood as a function of an individual person's sensory and social experiences within that place: Regarding Indianapolis, one author fondly recalls visiting the Slippery Noodle Inn, the oldest tavern in the state of Indiana; another author has only driven through "Indy" via U.S. Interstate 70 en route to another location; yet another has no knowledge of the city other than it occasionally hosts Big Ten college football tournaments. Notably, all three authors understand the name Indianapolis as a place, but each has their own sense of the place according to how they experienced it.

In this way, Tuan (1979) posits that an SoP is a uniquely human experience, and that individuals demonstrate their SoP when they apply their own moral and aesthetic assessments to a place. Relph's (1976) model suggests that SoP is developed based on the settings we find ourselves in, the activities that take place in those settings, the meanings that we attach to those activities, and a sense of character that we feel (a genius loci) for the place. Bott (2000) synthesizes across these and other perceptions of SoP (nearly 30 studies) to produce four specific domains in which an SoP can be assessed: the physical setting, the cultural setting, affective (emotional) factors, and functional assessments. Bott and others have engaged this explanation of Yuan's original conception in an attempt to quantify dimensions of SoP, although the very essence of SoP was simply meant to refer to "affective ties with the material environment” (Tuan, 1974, p. 93).

Given that SoP is idiosyncratic, we should expect quite a bit of variance among the senses of place that others have for the same area, although commonalities can, of course, be observed among subcultures or groups of individuals who might share other common values. For example, sports fans might engage in very similar sensory experiences associated with a baseball stadium: the smell of grilling hot dogs while gathered on a hot asphalt lot, wearing polyester/cotton blended replica jerseys of their favorite players, and filing through a cheering section chanting slogans and sharing seats on a hot aluminum bench - all seen as markers of fan avidity (DeSarbo \& Madrigal, 2011). These experiences likely contribute to a somewhat shared SoP for a baseball stadium among these fans. In addition, individuals native to a particular place draw heavily on their attachment to and identification with that place (concepts broadly analogous to SoP; Hernández et al., 2007), especially in the face of natural disasters (Chamlee-Wright \& Storr, 2009) and other existential disasters, such as climate change and other environmental threat (Albrecht et al., 2007; Burley et al., 2007; Hess et al., 2008). That said, Kohlbacher et al. (2015) find that while native status does lend itself toward higher place attachment, strong social ties help formulate place attachment for both natives and migrants alike, pointing to the potential for SoP to form independent of place-nativity.

\section{Transience and SoP}

Tuan (1979) further argues-in line with de Certeau (1984/ 1980) — that one can often only understand their SoP after leaving the place. That is, an SoP is a postconsumption reflection on the space one had previously visited, as well as their assessments of those experiences. To some degree, this reflective nature of SoP lends itself well to travel, as one's SoP for a location de facto transcends the physical place itself. By contrast, scholars such as Clifford (1996) suggest that tourism can be an authentic attempt at both self-reflection and cultural understanding, allowing tourists to serve the role of casual anthropologists. White and White (2004) discuss older traveler's motivations to tour the Australian Outback as a journey of self-transition, with affective motivations similar to older adults' preference for more meaningful and self-transcendental leisure experiences (such as entertainment media; Bartsch, 2012). Abou-Shouk et al. (2018) found that visitors to Egypt, who are able to foster an emotional relationship with their settings, are far more likely to return as the place becomes more self-referential. Importantly, however, as a sense, the place itself is less important than individuals' perceptions of the place (see Deutsch et al., 2013).

\section{Digital Environments and SoP}

Given that Yuan conceptualizes SoP as a personal connection to a location that transcends any actual location, it is reasonable to conclude that one can have the emotional connection within an SoP regarding nonactual (i.e., digital) spaces, so long as they can be visited in some sensory fashion. This begs the question of whether or not digital spaces may elicit similar senses of connection as do physical spaces. If Tuan's criteria boil down to companion mechanisms of abstract understanding (knowing the facts of a space) and affective familiarity (connecting with a space as one would a person), then game spaces arguably have the potential to engender SoP. Critical here is that our discussion is distinct from the creation of spatial presence in a digital world (Tamborini \& Bowman 2010), although we recognize that there is a probable (albeit not investigated in the current study) relationship between feeling physically located in a digital place and feeling an increased emotional connection with that place (see Turner \& Turner, 2006). Spatial presence is an illusion of "being there" in a digital place, whereas SoP reflects the emotional and idiosyncratic connections we form with that place.

Regarding the first criterion, video gaming communities and practices quite often focus on knowing the facts of games-relevant 
strategies, narrative backstories, and (most relevant here) the environments that players navigate and in which experience gameplay events unfold. Paratexts (those artifacts related to but constellated around the game proper; Consalvo, 2009) document the manifest facts of and strategies for dealing with game environments, such as topographic maps, nonplayer character paths, optimal character levels for particular regions, optimal routes for achieving game goals, map modifications, platforms for players to develop their own variations on maps, and even walkthroughs or tips for recognizing obscure objects or locations within complex environments. Indeed, exploration and documentation of spaces are understood to be a key motivator of gameplay (see Yee, 2006).

Regarding the second, video games and their environments are known to engender a range of emotions in players (see Hemenover \& Bowman, 2018), from feelings of awe upon encountering grand or otherworldly spaces (Possler et al., 2018) to senses of great loss when environments undergo dramatic changes brought about by game expansions (Banks \& Martey, 2018). Affective experiences are also understood to be both key motivators for engaging games (e.g., gratifications associated with relief from everyday life, affections for coplayers, empowerment from achievement; see Yee, 2006) and key demands of gameplay activities, drawing emotional resources from the player perhaps at the expense of being able to dedicate even physical or cognitive resources (Bowman, 2018).

Some developers go further in order to craft spaces that may be likely to engender SoP. They do so by adopting and acknowledging digital spaces' correlations with actual physical spaces or by integrating technological features that present opportunities for more intimately engaging an environment (Lentini \& Decortis, 2010). Despite the importance of emotions in activating attention and memory in interactive media, emotional engagement is thought by some to be comparatively weak, leading some interactive-storytelling designers to incorporate more purposeful emotional expression tools into interface designs (e.g., avatar facial expressions and gestures; Zagalo et al., 2006). To promote SoP in the course of promoting tourism, virtual reality environments simulating actual destinations may promote senses of authenticity and familiarity (see Guttentag, 2010). Such modeling of digital environments after actual environments holds the potential for SoP to develop for the actual environment, even for one who has never visited that physical space-so much so that users may even seek out additional information about or experiences with that space that helps to bolster or sustain SoP (see Williamson \& Roberts, 2010).

\section{Fallout 76 and SoP}

Off the heels of Fallout 4's success (the second-best opening sales weekend of any video game; Statistica, 2019), Fallout 76 was among the most highly anticipated video game releases in recent memory, with 2 million people viewing a day-long stream of the series, Vault Boy (a teaser for Fallout 76 that turned out to be an elaborate prank by the developers; Farokhmanesh, 2018). That the game was to be situated within the Appalachian Mountains was a major part of prerelease hype, an early foreshadowing of John Denver's "Country Roads" as the background music in a May 2018 teaser which sparked speculation that the game would have "a rural flair" (Good, 2018a, para. 15). As more details about the game's WV connection leaked, video game journalists archived fans' efforts to reconstruct the size and scope of Fallout 76
Appalachian location-Kuchera (2018) presented game maps from one Reddit user to estimate that Fallout 76 would include nearly 16 square miles of WV countryside, relying on regional landmarks that are both recognizable in their own right (such as the New River Gorge, one of the longest and tallest vehicular bridges in the world, and the golden dome of the WV State Capitol Building) and of specific relevance to Fallout's theme of surviving a postnuclear society (such as The Greenbrier, a world-renowned country club and professional golf course that secretly housed-up until 1992 - a nuclear fallout shelter designed to house the entire U.S. Congress and aids to survive nuclear war; Gup, 1992).

Some of this is not unique to Fallout 76, as previous games in the Fallout franchise were set in real-world locations such as Washington DC (Fallout 3) and Boston (Fallout 4). What makes Fallout 76 different is that the game is situated within the physical geography and authentic locations, as well as drawing from local folklore of WV, including The Mothman (the subject of a 2002 feature-length film The Mothman Prophecies), and lesser-known creatures such as the Grafton Monster and the Flatwoods Monster. Fallout 76 developers partnered with the West Virginia Tourism Board to "[show] the rest of the world what a gem West Virginia is" (West Virginia Governor Jim Justice, as cited by Griffith, 2018; para. 3), going so far as hosting launch parties at several of the game's actual-world locations, such as the aforementioned Greenbrier (Good, 2018b).

Notably, while mediated portrayals of Appalachia tend to engage pejorative stereotypes (Bowman \& Groskopf, 2010), Fallout 76's design - from its early marketing to the in-game experience — can be viewed through the lens of SoP scholarship. That is, Fallout 76 was designed not simply to provide a stereotypical portrayal of $\mathrm{WV}$ as a backdrop for the newest Fallout video game (as was the case with previous iterations of the franchise in which real-world locations were used more due to their recognizability), rather to challenge players to live in and survive an authentic Appalachian environment. As suggested by Good (2018b):

The hardiest people on earth are the hillbillies of Appalachia, and now my favorite video game franchise is giving them the center stage. We get to find out if we have what it takes to be one. (para. 13)

\section{Hypotheses}

Given that a strong SoP is more likely to be felt by individuals who have direct exposure and experience in a place, we expect broadly that natives to an area (in this case, those who live or have lived in WV) to be overall more likely to feel an SoP than those not native to an area. Formally, we predict that $(\mathrm{Hl})$ natives West Virginians playing Fallout 76 will self-report a greater SoP when thinking about WV than individuals from elsewhere.

Following this, it seems plausible that extended exposure to a place, digitally-here, playing Fallout 76 in a simulated WVwould also encourage an increased SoP for the actual, physical location. Thus, we predict that $(H 2)$ players' SoP when thinking about WV will increase over time, after playing Fallout 76.

Finally, given the two main-effect predictions above, we also examine the potential for an interaction effect. In particular, assuming that West Virginians are likely to have an overall higher SoP scores than non-natives, we also might expect natives to 
demonstrate less change in their SoP scores over time compared with non-natives. Given the knowledge and affect bases for SoP, and the opportunity to learn about and feel for the space through gameplay in fashions similar to opportunities in physical space, we anticipate that natives' and non-natives' SoP will converge over time, via gameplay. That is, we expect $(H 3)$ a disordinal and nonsymmetrical interaction by which the gap between native and non-native West Virginians will be greatest prior to playing Fallout 76, but will decrease in subsequent measures taken after playing the game (in this study, 2 weeks and 2 months following the start of gameplay).

Similarly, because knowledge is one of the two key sense-ofplace mechanisms, knowledge and recollection of actual locations represented in a digital environment become particularly relevant for considering how digitally derived SoP may foster tourism-related information-seeking behaviors. Broadly, we expect (H4) natives to be better than non-natives at recalling environment locations and, similar to our expectations of SoP above, (H5) the recollection gap between WV natives and non-natives will close over time, taking the form of a disordinal and nonsymmetrical interaction. Likewise, given that feelings of place tend to result in places becoming more meaningful and self-referential, we expect that (H6) higher SoP scores to be positively associated with a greater recollection of WV locations for all Fallout 76 players.

\section{Method}

As part of a larger mixed-method, longitudinal investigation into players' experiences with Fallout 76, the current study was grounded in players' SoP perceptions of WV over 3 months' time: 2 weeks prior to the game's release (T1), 2 weeks following the game's release (T2), and 2 months following the game's release (T3). Copies of all survey materials, data output files, and anonymous versions of the other conference manuscripts from this data set (for reference and comparison) are available online at https://osf.io/ n9dw5 (Bowman et al., 2020). The study protocol, including data sharing practices, was approved by the host institution's institutional review board.

For study recruitment, we used a variety of social media outlets to broadly advertise our study, advertised as "academic research about West Virginia and Fallout 76." Links to the study were posted in six Reddit communities (with moderator approval). We also purchased $\$ 500$ in Facebook advertising credits, targeting individuals aged 18 and older from Fallout and Fallout 76 Facebook pages; these ads were shared organically in Facebook users' personal network, as well as on Instagram and via Facebook messenger. Finally, links to the study were also shared on the study authors' personal social media pages (Facebook and Twitter), as well as in various gaming and academic research communities. All advertisements were shared during the first 2 weeks of November 2018, immediately preceding the release of Fallout 76 (14 November 2018); the survey was closed once the game was released.

\section{Participants}

For the current study, our analyses focus on $N=556$ participants who completed all three surveys (T1, T2, and T3). Participants average age was $M=30.7(S D=8.67), 89 \%$ of the sample selfidentified as white or Caucasian ( $n=489$, open-ended question), $89 \%$ ( $n=545$, open-ended question) lived in the United States
( $n=545$, open-ended question), and $68 \%$ of the sample selfidentified as male ( $n=378$, open-ended question). Participants were politically neutral, $M=3.64$ ( $S D=1.83$, on a single-item scale, with " 1 " indicating more liberal and " 7 " indicating more conservative). Just under $24 \%$ of the sample $(n=133)$ was either born, currently lives, or have lived in WV (referred to as "natives" for the current study).

With respect to video game experience, participants in this sample played video games for $M=24.47 \mathrm{hr} /$ week $(S D=15.59)$ and had been playing video games for $M=20.29$ years $(S D=8.84)$. This sample self-reported an overall high level of fandom for the Fallout franchise, $M=9.12$ ( $S D=1.29$, with " 0 " as the lowest and " 10 " as the highest score).

\section{Measures}

Time spent playing Fallout 76 was assumed to increase as cumulative during the three waves of the study, and as such the within-subjects measurement points serve as natural comparison points in the study (the three time-ordered measures of SoP, explained below). However, participants were asked to record their cumulative time spent playing Fallout 76 at the second survey ( $M=71.84, S D=58.85$; this includes alpha and beta releases $)$ and the third survey $(M=107.79, S D=91.91)$. As expected, pairedsamples $t$-test demonstrates that overall, cumulative time spent playing at the third survey was higher than time spent playing at the second survey, $t(555)=12.67, p<.001$, Cohen's $d=.772$.

All participants had played Fallout 76 for at least $1 \mathrm{hr}$ as of the second survey. We also assessed how many individuals were still playing the game as of the third survey. Just under three-fourths of the survey, or $73.5 \%$ of T2 participants $(n=409)$, self-reported that they were still playing the game as of the third survey, and $76.3 \%$ $(n=424)$ reported total hours spent playing that were higher at T3 than at T2. However, we did observe that more than $20 \%$ of players reported a T3 cumulative gameplay-time score that was smaller than their T2 cumulative score, and this might have been due to misunderstanding the question (reporting time "since the last survey" instead of "including all previous surveys"). As a result, we were not satisfied with the validity of the T3 cumulative hours spent playing scores, and instead, cumulative hours spent at $\mathrm{T} 2$ were considered in the analysis, as was the player's self-report of whether or not they were still playing Fallout 76 at T3. As an additional robustness check, we compared overall game rating scores (on a scale of "1" to "100") between individuals still playing and no longer playing Fallout 76 at T3, and an expected significant difference was found such that those still playing $(M=75.90, S D=1.15)$ rated the game higher than those no longer playing $(M=56.47, S D=20.67)$, $t(217.88)=10.15, p<.001$, Cohen's $d=1.33 .{ }^{1}$

$S o P$ was assessed using the affective individual and personal domain dimensions suggested in Bott (2000), as they are most closely aligned with Tuan's original SoP concept. A total of 29 items, each on seven-point Likert scales, were used to assess participants' perceptions of significance, existential association, memory, aesthetic, and transcendence in relation to WV. This five-factor model, which was

\footnotetext{
${ }^{1}$ The correlation between sense of place scores and overall game rating was moderate and significant, $r(541)=.307, p<.001$. A correlation of this magnitude suggests that the two concepts covary (as would be expected) but are not isomorphic.
} 
not supported by confirmatory factor analysis, did not support her suggestions: Time $1 \mathrm{CMIN} / \mathrm{df}=4.95, \mathrm{CFI}=.882$, $\mathrm{RMSEA}=.084$; Time $2 \mathrm{CMIN} / \mathrm{df}=5.47, \mathrm{CFI}=.865, \mathrm{RMSEA}=.090 ;$ and Time 3 $\mathrm{CMIN} / \mathrm{df}=5.61, \mathrm{CFI}=.869, \mathrm{RMSEA}=.091$. Moreover, factor correlations ranged from $r=.631$ to $r=.983$ at Time $1, r=.500$ to $r=.981$ at Time 2, and $r=.542$ to $r=.963$ at Time 3 (see supplemental files for details).

For this reason, exploratory factor analysis using principal axis factoring and direct oblimin rotations was performed on the SoP items, individually, for all three administrations of the scale. All three administrations met minimum standards of sampling adequacy: Time $1 \mathrm{KMO}=.974$, Bartlett's $\chi^{2}(435)=13259.9, p<.001$; Time 2 $\mathrm{KMO}=.971$, Bartlett's $\chi^{2}(435)=13231.0, p<.001 ;$ and Time 3 $\mathrm{KMO}=.973$, Bartlett's $\chi^{2}(435)=14046.8, p<.001$. The unrotated factor solution for all three administrations showed that 13 of the original 30 items both (a) loaded strongly onto a primary underlying factor (factor loadings $>.600$ ) and (b) this pattern of factor loadings was consistent across all three uses of the scale (see Table 1). Further inspection of the rotated factor solution showed a substantial loss of explained variance from the primary factor to the next (primary eigenvalue $\sim 15.00$ for the first factor, an eigenvalue reduction of $\sim \Delta 13.00$ for the second factor, and any other eigenvalues $<1.00$ for subsequent factors). Following the recommendations of Bowman and Goodboy (in press), we formalized a unidimensional measure of SoP using these 13 items. ${ }^{2}$ Complete exploratory factor analysis results are available in our supplemental files.

Finally, participants were asked at all three points in time to list as many places in $W V$ that they could. Fifty-two percent of respondents ( $n=287$ of 553 replies) recalled at least one actual-world WV location at T1 (prior to gameplay), $83 \%$ of respondents ( $n=451$ of 542 total replies) did at T2, and 84\% ( $n=430$ of 512 total replies) did at T3. ${ }^{3}$ For coding these responses, we read each participant's open-ended answer and coded them into binary categories: "0" if they could not name a specific location and " 1 " if they named at least

\section{Table 1}

Univariate Factor Solution for Revised Sense of Place Measure

\begin{tabular}{|c|c|c|c|}
\hline Item & $\begin{array}{l}\text { Primary } \\
\text { factor } \\
\text { loading, T1 }\end{array}$ & $\begin{array}{l}\text { Primary } \\
\text { factor } \\
\text { loading, T2 }\end{array}$ & $\begin{array}{c}\text { Primary } \\
\text { factor } \\
\text { loading, T3 }\end{array}$ \\
\hline \multicolumn{4}{|c|}{ Stem: "West Virginia makes me feel..." } \\
\hline$\ldots$ a sense of connection & .828 & .804 & .789 \\
\hline$\ldots$ inspired & .852 & .866 & .858 \\
\hline$\ldots$ fulfilled & .823 & .829 & .828 \\
\hline$\ldots$ a sense of appreciation & .799 & .808 & .818 \\
\hline$\ldots$ alive & .817 & .830 & .822 \\
\hline$\ldots$ a spirit of place & .752 & .765 & .757 \\
\hline$\ldots$ a sense of awe & .817 & .777 & .816 \\
\hline$\ldots$ a sense of romance & .674 & .686 & .711 \\
\hline \multicolumn{4}{|l|}{ Stem: "For me, West Virginia is } \\
\hline$\ldots$ inspirational & .767 & .779 & .803 \\
\hline$\ldots$ meaningful & .763 & .766 & .756 \\
\hline ... magical & .745 & .731 & .775 \\
\hline$\ldots$ sacred & .694 & .631 & .737 \\
\hline ... memorable & .691 & .676 & .706 \\
\hline Unique variance explained & $58.97 \%$ & $58.98 \%$ & $61.46 \%$ \\
\hline
\end{tabular}

Note. Participants completed the sense of place measure at three points in time during this study. $\mathrm{T} 1=$ First scale administration; $\mathrm{T} 2=$ second scale administration, $\mathrm{T} 3=$ third scale administration. one specific location. Only rarely (13 times) did participants report a false-positive-a recollection of a location that does not actually exist in WV. In seven of these cases, participants did list other authentic locations and, thus, were coded as "1."4 Participants" vague descriptions of places (such as "state capitol") were counted as a recollection if we could intuit the location's real-world correlations (e.g., "the giant teapot" is a clear reference to the World's Largest Teapot in Chester, WV; the real-word location recollection does not have a common or official name).

\section{Results}

For data analysis, we tested $\mathrm{H} 1-\mathrm{H} 3$ using a repeated-measures ANOVA with WV native status as a between-subjects and SoP measures as between-subjects measures. H4 and H5 were tested using a repeated-measures ANOVA with WV native status as a between-subjects and place recollection binary codes as betweensubjects measures. Notably, as our study design assumed participants to still be playing Fallout 76 at T3 (we did not anticipate individuals no longer playing the game to still be interested in completing our survey), all primary tests of $\mathrm{H} 1-\mathrm{H} 5$ were performed using participants still playing the game at T3. However, each test was supplemented with a parallel analysis of participants no longer playing the game at T3. For H6, partial correlations were used to examine predicted covariance between SoP scores and recollection scores - tested at both $\mathrm{T} 2$ and $\mathrm{T} 3$ - controlling for $\mathrm{WV}$ native status.

\section{Primary Tests of $\mathrm{H1}-\mathrm{H3}$}

A repeated-measures analysis of variance was used to test the influence of being a native West Virginian on respondents' felt SoP associated with WV across three administrations of the SoP scale: prior to playing Fallout 76, within 2 weeks of the game's initial release, and 2 months after game's release. Notably, measures of players' actual time spent playing the game (aggregate hours at T2 and T3) were taken as well as their self-reported active play at T3. However, neither of the aggregate hours spent playing measures were associated with any of the three SoP measures. Player's selfclassification at T3 as ongoing Fallout 76 players was correlated with T3 $\operatorname{SoP}(r=.152, p<.001)$. However, given that this measure would only be applicable at T3, it would be illogical to use it as a covariate or as a between-subjects factor (as the measure cannot have any influence on T1 or T2 SoP scores). Thus, analyses here are a mixed-measures ANOVA with one between-subjects measure (WV native status) and one within-subjects measure (SoP measured

\footnotetext{
${ }^{2}$ As further evidence of the scale's unidimensionality, we note that our single-factor sense of place scale includes items from each of Bott's five suggested sense of place factors-in other words, although Bott $(2000)$ asserted that these items should measure conceptually and empirically unique aspects of sense of place, our factor analysis does not support this assertion.

${ }^{3}$ The West Virginia Tourism Office has created an interactive map of all of the real-world WV locations in Fallout 76, available online at https:// wvtourism.com/fallout76/fallout76-interactive-map/?preview=true. For readers interested in the specific WV locations that study participants recalled, and that data are available in our supplemental files, shared at https://osf.io/n9dw5/.

${ }^{4}$ The most common false-positive was participants naming Vault 76 (the starting point of the video game and the game's namesake; $k=6$ ). Some have argued that Vault 76 has a resemblance to Coopers Rock State Part, but this is likely a coincidence.
} 
3 times): our primary hypothesis tests being conducted on those still playing Fallout 76 at T3 $(n=399, n=300$ natives, and $n=99$ non-natives) and supplemental analyses on those who are no longer playing at T3 ( $n=142, n=33$ natives, and $n=112$ non-natives).

For individuals still playing Fallout 76 at T3, there was a multivariate main effect of time on SoP, Pillai's trace $=.053, F(2,396)=11.06$, $p<.001$, partial $\eta^{2}=.053$, as well as a multivariate interaction effect of time and WV native status, Pillai's trace $=.046, F(2,396)=9.54$, $p<.001$, partial $\eta^{2}=.046$. The main effect of $\mathrm{WV}$ native status on SoP was significant, $F(1,397)=18.13, p<.001$, partial $\eta^{2}=.044$. SoP scores were lower for non-WV natives $(M=4.84, S D=1.20)$ than WV natives $(M=5.28, S D=1.13)$, supporting $H 1$. The main effect of elapsed time on SoP was also significant, GreenhouseGeisser $F(1.45,575.94)=4.48, p=.001$, partial $\eta^{2}=.011 .^{5}$ The main effect of time followed a linear trend, $F(1,397)=21.83$, $p<.001$, partial $\eta^{2}=.052$, with post hoc testing showed scores at $\mathrm{T} 1(M=4.93, S D=1.38)$ and T3 $(M=5.16, S D=1.36)$ to differ significantly, $p<.001$, but scores at T2 $(M=5.09, S D=1.36)$ to be statistically similar to T1 $(p=.068)$ and T3 $(p=.482)$. These scores offer support for H2. To test the disordinal interaction effect, the within-subjects interaction effect of time with WV natives was significant, Greenhouse-Geisser $F(1.45,575.94)=8.56, p=.001$, partial $\eta^{2}=.021$, and followed a quadratic trend, $F(1,397)=8.10, p=.005$, partial $\eta^{2}=.020$. However, visual inspection of this interaction in Figure 1 shows that SoP scores differed at T1 such that WV natives were significantly higher that non-natives. This gap closed at T2, but re-emerged (albeit to a smaller degree) at T3. However, and most critically for our predictions, SoP scores for WV non-natives at T3 were significantly higher than at $\mathrm{T} 1$ and did not differ significantly from $\mathrm{T} 2$ scores, offering support of $\mathrm{H3}$.

\section{Supplemental Tests of H1-H3}

As participants offered a self-report of whether or not they were still playing Fallout 76 at T3 (the end of our study) and because all responding participants were playing the game as of T2, we can analyze the subset of $n=142$ games who stopped at T3 as a natural comparison group for our study. For these participants, the multivariate main effect of time was not significant, Pillai's trace $=.017$, $F(2,139)=1.23, p=.296$, partial $\eta^{2}=.017$, and neither was the multivariate interaction of time and WV native status, Pillai's trace $=.041, F(2,139)=3.00, p=.053$, partial $\eta^{2}=.041$. For this second effect, we note, however, that the observed effect size is only nominally different from the same effect size (.046) of the first test; likewise, Pillai's traces are similar (.046); thus, the failure of this test to reach the $p<.05$ significance level is likely due to the fact that the test contains $25 \%$ fewer data points and, thus, was underpowered (observed power $=.573$, compared with an observed power of .980 for the same analysis reported above). That said, a main effect for WV native status on SoP was observed, $F(1,140)=14.92$, $p<.001$, partial $\eta^{2}=.096$, with $\mathrm{WV}$ natives reporting overall higher SoP $(M=5.20, S D=1.12)$ than non-WV natives $(M=4.58$, $S D=1.18$ ), offering further support for $H 1$. However, follow-up inspection of within-subjects effects failed to reach statistical significance for the main effect of time (Greenhouse-Geisser $p=.148$ ) or the interaction of time and WV native status (Greenhouse-Geisser $p=.091$ ). Closer inspection of Figure 1 (right side) demonstrates that for non-WV natives, T2 SoP did increase significantly from T1 scores, but those scores dropped at T3. It is possible that non-WV natives who stopped playing Fallout 76 at T3 would likely lose any connection with WV as a meaningful place. To further tease this effect out, the analyses were recalculated with only $\mathrm{T} 1$ and $\mathrm{T} 2$ scores, and here the multivariate interaction effect of time and $\mathrm{WV}$ native status was significant, Pillai's trace $=.035, F(1,143)=5.12$, $p=.025$, partial $\eta^{2}=.035$, and this test clearly demonstrates that although T1 SoP differed significantly between WV natives $(M=5.26, S D=1.08)$ and non-natives $(M=4.29, S D=1.18)$, this difference is nonsignificant at $\mathrm{T} 2$, with scores for natives $(M=5.14, S D=1.15)$ and non-natives $(M=4.95, S D=1.24)$ statistically equal, and notably both higher than non-native SoP scores at T1. This finding offers further support for $\mathrm{H3}$.

\section{Primary Tests of $\mathrm{H4}$ and $\mathrm{H5}$}

To test the predictions that (H4) WV natives would be more likely to recall at least one authentic WV place than non-natives and that (H5) this expected gap would close over time, we performed a mixed-design ANOVA with WV native status as a between-subjects variable and the three WV place recollection responses as withinsubjects dependent variables. As with the above analyses, these analyses were run twice: once for individuals who were still playing Fallout 76 at T3 (our primary analysis) and once for individuals who stopped playing the game at T3 (supplemental analysis). Observed means are displayed in Figure $2{ }^{6}$

For those still playing the game at $\mathrm{T} 3$, there was a multivariate main effect of time on recall scores, Pillai's trace $=.142, F(2,370)=30.56$, $p<.001$, partial $\eta^{2}=.142$. There was also a significant multivariate interaction effect of time and WV native status, Pillai's trace $=.028$, $F(2,370)=5.25, p=.006$, partial $\eta^{2}=.028$. Focal to $\mathrm{H} 4$ was the significant between-subjects effect of WV native status on place recall, $F(1,371)=10.81, p=.001$, partial $\eta^{2}=.028$, in which WV natives $(M=83.0 \%, S D=.24)$ were more likely to recall WV locations than non-natives $(M=73.2 \%, S E=.24)$-these data offer support for $\mathrm{H} 4$. Moreover, the within-subjects interaction effect of time and WV native status was significant, Greenhouse-Geisser $F(1.92$, $713.44)=6.28, p=.002$, partial $\eta^{2}=.017$, and the effect followed a quadratic trend, $F(1,371)=5.69, p=.018$, partial $\eta^{2}=.015$, showing evidence of the predicted disordinal effect. Visual inspection of this interaction in Figure 2 (top-left and bottom-left) shows WV recollection scores differing significantly at $\mathrm{T} 1$ with $\mathrm{WV}$ natives recalling significantly more WV locations than non-natives, but that this gap closes at T2 (with non-natives' recollection scores increasing to WV native levels) and the gap remains closed at T3, in support of $\mathrm{H} 5$.

\footnotetext{
${ }^{5}$ The Greenhouse-Geisser index was interpreted here due to a violation of sphericity, Mauchly's $W=.621, \chi^{2}(2)=188.4, p<.001$, GreenhouseGeisser $\varepsilon=.725$.

${ }^{6}$ During the revision process, an observant reviewer suggested that we revisit our coding for errors and in fact, we did find evidence of miscoded data: 28 codes for the first survey, four codes in the second survey, and four codes in the third survey. In all cases, participants gave answers that we deemed overly vague on reconsideration (such as listing "Appalachia" as a place; this was most prevalent in the first survey). For full transparency, we have updated our shared data file to include the original and revised coding results. Notably, these coding errors had no appreciable influence on the conclusions drawn from our initial analysis, but we have updated all statistical results. The original and revised results are also included in our supplemental documentation.
} 
Figure 1

Participants' Sense of Place Perceptions as a Function of West Virginia Native Status, for Individuals Still Playing (Left) and No Longer Playing (Right) Fallout 76 at the Study Conclusion

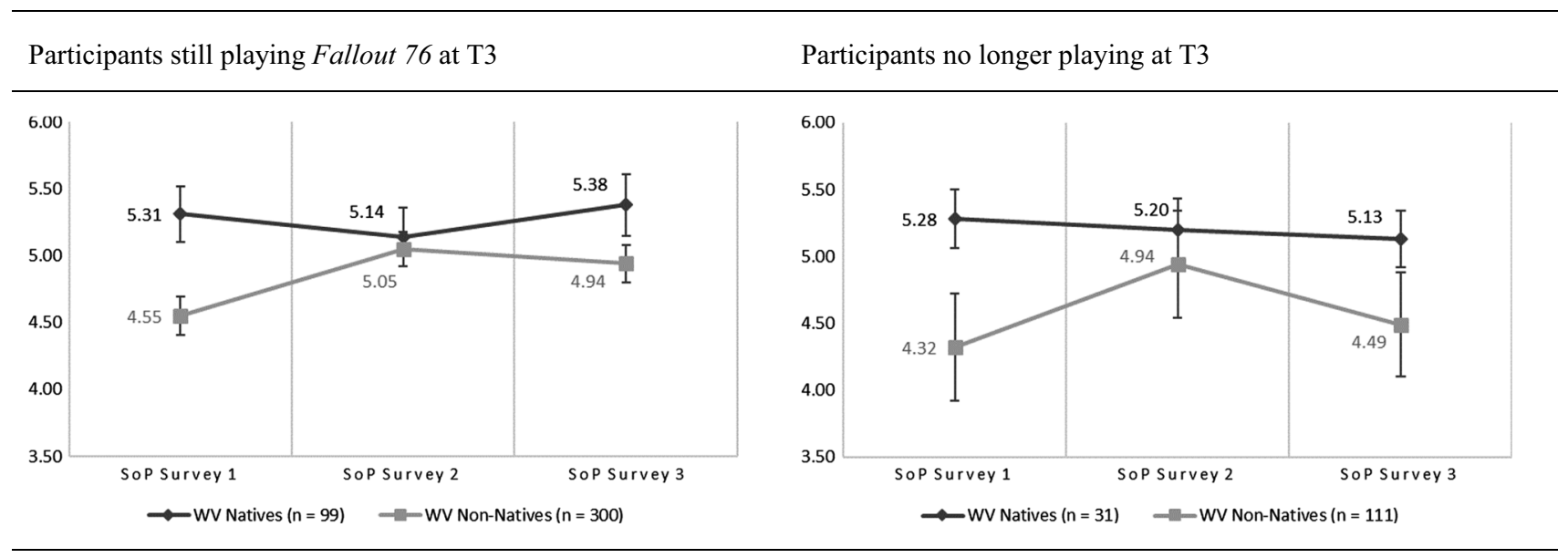

Note. Figures have been drawn with $95 \%$ confidence intervals around observed means, and chart scaling is exaggerated to simplify visual interpretation of confidence intervals.

\section{Supplemental Tests of $\mathrm{H4}$ and $\mathrm{H5}$}

As with analyses of SoP (H1-H3), the analyses of $\mathrm{H} 4$ and $\mathrm{H} 5$ above were replicated for the subset of participants who were no longer playing Fallout 76 at T3. It is possible that the empirical support for $\mathrm{H} 4$ and $\mathrm{H} 5$ uncovered above could be lost if players are no longer playing the game.

Unlike the results of $\mathrm{H} 1-\mathrm{H} 3$ above, the supplemental analyses here were a bit more difficult to interpret due to the wider confidence intervals around the observed means for WV natives. As with the main analysis, there was a multivariate main effect of time on recol- lection scores, Pillai's trace $=.180, F(2,121)=13.29, p<.001$, partial $\eta^{2}=.180$. The within-subjects effect was significant, Greenhouse-Geisser $F(1.93,235.50)=13.18, p<.001$, partial $\eta^{2}=.099$, and the effect followed a quadratic trend, $F(1,122)=$ $8.04, p=.005$, partial $\eta^{2}=.062$. For both natives and non-natives, recollection scores were lowest $(M=.53, S D=.61)$ at $\mathrm{T} 1$, improved drastically $(M=.85, S D=.43)$ at $\mathrm{T} 2$, and decreased slightly but nonsignificantly at $\mathrm{T} 3(M=.79, S D=.53)$. For players who stopped playing Fallout 76 at T3, we can conclude that the only influence on their ability to recall WV locations was playing the

\section{Figure 2}

Participants' Recollection of West Virginia Locations as a Function of West Virginia Native Status, for Individuals Still Playing (Left) and No Longer Playing (Right) Fallout 76 at the Study Conclusion

Participants still playing Fallout 76 at T3

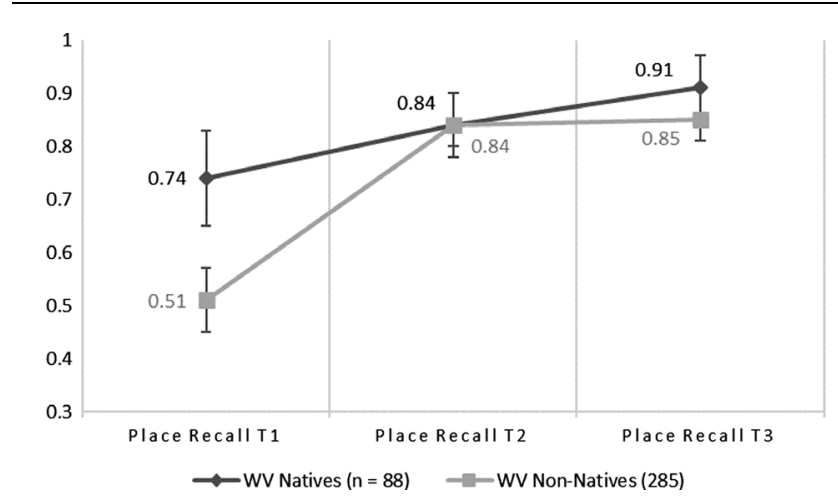

Participants no longer playing at $\mathrm{T} 3$

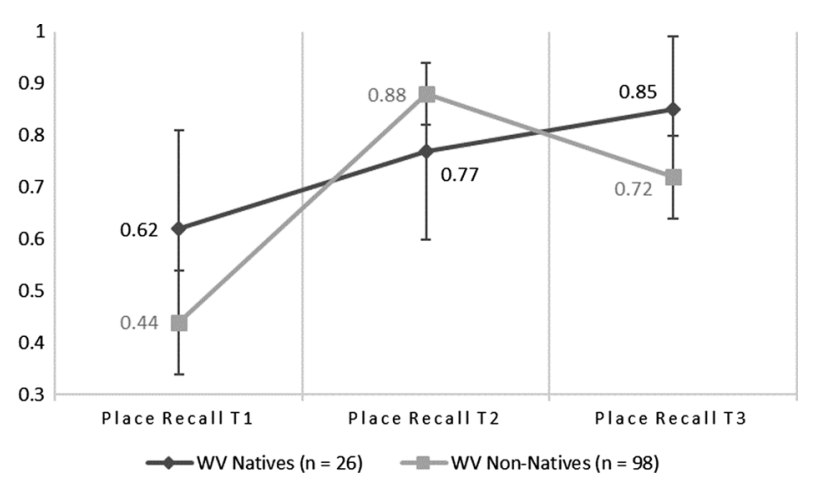

Note. Figures have been drawn with $95 \%$ confidence intervals around observed means, and chart scaling is exaggerated to simplify visual interpretation of confidence intervals. 
game over time, but the lack of expected differences between recall for natives and non-natives (particular at $\mathrm{T} 1$, where the mean difference trended in the expected direction, but there was more variance than expected in the WV native group) does not offer additional insights into $\mathrm{H} 4$ and $\mathrm{H} 5$.

\section{Testing H6}

Our final analysis considered the broad association between SoP for WV and recollection of WV locations after gameplay, controlling for WV native status. For players who were still playing Fallout 76 , the correlations were significant both 2 weeks after playing (T2), $r(370)=.248, p<.001$ and two months after continued play (T3), $r(370)=.175, p=.001$, supporting H6. For participants who were no longer playing at $\mathrm{T} 3$, the correlation was significant at $\mathrm{T} 2$, $r(121)=.228, p=.011$, but nonsignificant at $\mathrm{T} 3, r(121)=.090$, $p=.324$, further supporting $H 6$.

\section{Discussion}

Data from the current study suggest that playing a video game based on an actual-world environment does indeed boost both affective attachment toward and better recall for locations in that environment. This effect is such that although natives have expectedly higher SoP before gameplay, both metrics (affect and knowledge) converge between natives and non-natives over time. Through sustained play with Fallout 76 across two months' time, non-native West Virginians felt an SoP for WV on par with natives of the state.

\section{SoP as Materiality-Agnostic}

Differences between natives and non-natives SoP (H1) and identification of specific WV locations within the game (H4) are consistent with assertions that prior experience with the actual physical place being depicted may enhance one's acuity to identify it and remember it in the virtual world and to feel a connection to that place through gameplay. Importantly, in this, players were asked to evaluate actual WV based on their cumulative native (actual + digital) or non-native (digital-only) experiences, such that the convergence of SoP according to the two experiential anchors allows for claims that postplay SoP for non-natives emerged entirely out of digital space experiences. In other words, SoP emerging from the digital environment experience transferred to evaluations of the physical environment itself on par with those who had actual experiences in actual WV spaces. This is interpreted to suggest that SoP emerges agnostic of contact with the physical space (in line with Tuan, 1974) and, consequently, may rely on affect associated with one's mental model for the space rather than the space itself (see Valiquette \& McNamara, 2007). SoP may best be conceptualized as an affective attachment to and knowledge of one's apprehension of a space, independent of (or least not dependent on) physical inputs from a space (e.g., smells, tactile features). Such a conceptual extension is critical for the study of digital SoP experiences.

Interpreting SoP as materiality-agnostic should be considered in relation to this study's findings on nativity. Ostensibly, those native to a place rendered in-game should have stronger affective connections to it (as supported in $\mathrm{H} 1$ and $\mathrm{H} 4$ findings) given extant perspectives on the link between social identities and SoP (cf. Twigger-Ross \& Uzzell, 1996). That the experiences in the digital game world were sufficient to override natives' advantage suggests that either (a) SoP does not rely heavily on social identities (here, a held identity as an Appalachian) or (b) the game's aesthetic and narratives were sufficient to build a "virtual" social identity via gameplay as an Appalachian. Future research should endeavor to unpack these mechanics toward differentiating between potential egoistic and environmental production of SoP, and whether any phenomenological differences may emerge from those mechanics.

\section{Temporal Considerations}

In comparing SoP and recall measures between $\mathrm{T} 2$ and $\mathrm{T} 3$, we found that players who had stopped playing had significantly lower scores at $\mathrm{T} 3$ than those who had continued playing over the course of the study. This finding can be interpreted two ways. First, it is possible that for non-natives, the SoP scores may have dropped at T3 (returning to pregameplay levels) as a function of having no longer played Fallout 76. That is, when one stops being exposed to that environment, the attachment to the place is likewise broken. Second, it is possible that when players do not feel a sense of affective attachment to or knowledge of a place, it moves them to stop playing the game. At least one motivation for gameplay is the promise of immersion in and escape to fantasy environments (Yee, 2006), so it is plausible that when that promise is unfulfilled (i.e., when the game environment does not engender feelings of attachment) that players will no longer be motivated to play the game. Although this study's design does not allow for the disentangling of these two causal claims, it is a meaningful direction for future research as the former (ceased gameplay results in broken SoP) has implications for those aiming to use gaming and virtual worlds to connect users to places, and the latter (broken SoP results in ceased gameplay) has implications for the attention game developers should pay to crafting environments that engender strong senses of place to encourage gameplay. Additional considerations might include how long SoP lasts after gameplay has ended, as well as how game narratives might play a unique role in SoP engagement and sustainment. The latter point is critical given that game narratives tend to trigger more meaningful and introspective emotional reactions, which could extend to the places hosting that content (Oliver et al., 2016).

\section{Limitations and Future Research}

In addition to standard limitations of longitudinal and fieldwork (such as attrition and a reliance on self-reports) and suggestions for future work already noted above, there are a number of theoretical and practical limitations of this study that should be considered. Most notably, this work did not consider the role of presence in the link between digital environment exposure and SoP. As a first step to understanding the links between gameplay and affective attachment, we focused only on emotional connections between player and place, in line with Tuan's operationalization of SoP as the focal outcome. However, psychological processes known as key to gameplay experiences could moderate the relationship. In particular, feelings of presence - particularly spatial presence — might accelerate or enhance emotional connections with place. Indeed, after virtual reality experiences, descriptions of environmental features and interpreted meaning of the spaces are among the two most 
salient considerations, including affective dimensions (Turner \& Turner, 2006). It is possible that although conceptually distinct (spatial presence - the illusion of being there; and $\mathrm{SoP}$ - an affective connection resulting from), the two may be concomitant. Importantly, because the non-natives' ability to develop SoP independent of physical exposure to the place points to the potential role of spatial presence in terms of formulating a sense of being there, following Tuan's (1974) sentiment that the place itself is not actually central to SoP. Future work should consider parceling out presence and SoP to articulate the relationship or distinction between the experiences.

Following, it is also possible that social presence (the sense of being together with others; Lombard \& Ditton, 1997; applied to video games in Tamborini \& Bowman, 2010) may contribute to the SoP, as the interactions we have in a place may make them the places more meaningful to us (e.g., a particular bench in a particular city in an online game because meaningful when two roleplayers' characters become engaged there-not because of the bench itself, but because of its relevance to the social activity that occurred there). Indeed, social presence builds senses of community which can be important to SoP (Walker, 1999), and mental models for media environments and narratives may rely on characters present and events that unfold there (Bower \& Morrow, 1990). In tandem, selfpresence (feeling the self-represented in a space; Lombard \& Ditton, 1997; Tamborini \& Bowman, 2010) may be of import, given that self-relevance is known to engender feelings of appreciation (Oliver \& Raney, 2011), such that affective attachment may be bolstered when people see themselves embedded in or impacted by the digital space. Related to this, there might be potential for SoP to also trigger social identity effects (Tajfel \& Turner, 1986), given that places have heuristic power to trigger identities (e.g., Kteily et al., 2019). Here, SoP could have potential to reduce negative attitudes about both those places and the people who inhabit them (Nadler et al., 2009) — particularly relevant for Fallout 76 given largely pejorative stereotypes commonly held toward Appalachia (the place) and Appalachians (the people; Massey, 2007).

The interpreted findings and speculations about the role of presence in SoP hold implications for a range of behavioral outcomes, such as emotional health (e.g., diversions associated with temporary escapes from daily stress; Reinecke, 2009) and tourism (connecting with a space which may then drive motivations to actually visit the locale; Xu et al., 2013). SoP has been investigated in educational settings (Park, 2018; Wen \& Looi, 2019), and might also be useful in helping craft a deeper understanding of how users experience fully virtual experiences (Bruns \& Chamberlain, 2019). Rizzo et al. (2009) rendered authentic places as part of virtual reality exposure therapy (in his work, for treating military veterans coping with posttraumatic stress disorder), and this work could be augmented with a deeper understanding of SoP for both the virtual worlds and their real-world analogs. Considering the increasingly widespread rollout of immersive technologies such as video games and virtual reality that seek to render and replicate both corporeal and fictitious locations, adopting an SoP perspective to better understand how users connect with places is likely a crucial mediating or moderating variable for work hoping to better understand the phenomenology of digital worlds.

One concept left unexplored in the current study is the extent to which the SoP that one fosters in a digital environment is reciprocal. Our study assumes that gameplay is what fosters SoP for the physical place, but it is just as logical that individuals with prior exposure to a place might turn to a digital rendition to rekindle their SoP. A few of our study participants talked about being motivated to play Fallout 76 because it provided them an opportunity to (paraphrasing) "return back home" or "return to Appalachia." Such an effect is somewhat synonymous with the reciprocal links between human contact with a person from an outgroup and positive affect toward that individual's entire outgroup, with several studies revealing this bidirectional prejudice-contact dynamic that may also be present with SoP and physical tourism (e.g., Swart et al., 2011). Somewhat related to this, one might question the influence of prior fanship or avidity toward the content to influence SoP feelings-in this case, perhaps fans of the broader Fallout franchise are inclined to feel a stronger SoP. At least in our data, such concerns were unfounded given that Fallout franchise fandom and SoP were uncorrelated at both T2, $r(555)=.016, p=.712$ and $\mathrm{T} 3, r(540)=$ $.058, p=.175$. That said, future work might take a more nuanced approach to understanding these relationships.

The current study used a free recall task in which participants were asked to recall as many WV locations as they could. One alternative to such a task in future research might be the use of a recognition task-showing participants' locations from the digital or physical places and testing their recognition accuracy (e.g., by including "foil" places in the same task). However, it is important to revisit Tuan's original conceptualizations of SoP here, noting that individuals can have deep and emotional connections with places even if they cannot recall specific attributes (such as names of locations) of those places. That is, one can have an emotional bond with a place that they do not have detailed recognition of, and one can also have detailed recognition of a place and lack emotional connection to it.

\section{Conclusion}

SoP is understood as an emotional and deeply personal connection that one has toward the many different places in which they live and have experienced (Tuan, 1974, 1975, 1979). Early work on SoP focused on physical locations, but as digital places become more complex and easier to access, those hoping to understand user experience might benefit from exploring the SoPs that users develop toward these digital locales. For the current study, experiencing a digital place resulted in an increased SoP for a physical world location. Such a finding extends Tuan's earliest intuitions that SoP is less about materiality and more about how individuals internalize and experience what they see as authentic. As communication technologies expand to provide access (at varying degrees of immersiveness) to novel places, our data suggest that these digital visits could foster authentic connections.

\section{References}

Abou-Shouk, M. A., Zoair, N., El-Barbary, M. N., \& Hewedi, M. M. (2018). Sense of place relationship with tourist satisfaction and intentional revisit: Evidence from Egypt. International Journal of Tourism Research, 20(2), 172-181. https://doi.org/10.1002/jtr.2170

Albrecht, G., Sartore, G.-M., Connor, L., Higginbotham, N., Freeman, S., Kelly, B., Stain, H. Tonna, A., \& Pollard, G. (2007). Solastalgia: The distress caused by environmental change. Australasian Psychiatry, 15(Suppl. 1), S95-S98. https://doi.org/10.1080/10398560701701288 
Banks, J., \& Martey, R. M. (2018). Coping with [r]evolution in online games: Vulnerability and resilience responses to perceived risk in MMO game expansions. Journal of Broadcasting \& Electronic Media, 62(2), 269286. https://doi.org/10.1080/08838151.2018.1451852

Bartsch, A. (2012). As time goes by: What changes and what remains the same in entertainment experience over the lifespan? Journal of Communication, 62(4), 588-608. https://doi.org/10.1111/j.1460-2466.2012.01657.x

Bott, S. E. (2000). The development of psychometric scales to measures sense of place [Unpublished doctoral dissertation]. Colorado State University.

Bower, G. H., \& Morrow, D. G. (1990). Mental models in narrative comprehension. Science, 247(4938), 44-48. https://doi.org/10.1126/science .2403694

Bowman, N. D. (2018). Video games: A medium that demands our attention. Routledge.

Bowman, N. D., Banks, J., \& Rittenour, C. (2020). A longitudinal analysis (two months) of Fallout 76 players [Data repository]. Center for Open Science. https://doi.org/10.17605/OSF.IO/N9DW5

Bowman, N. D., \& Goodboy, A. (in press). Evolving considerations and empirical approaches to construct validity in communication science. Annals of the International Communication Association.

Bowman, N. D., \& Groskopf, J. (2010). Appalachia: Where the Squids hate the Chalkies. KBJournal, 7(1). https://www.kbjournal.org/bowman_groskopf

Bruns, C. R., \& Chamberlain, B. C. (2019). The influence of landmarks and urban form on cognitive maps using virtual reality. Landscape and Urban Planning, 189, 296-306. https://doi.org/10.1016/j.landurbplan.2019.05.006

Burley, D., Jenkins, P., Laska, S., \& Davis, T. (2007). Place attachment and environmental change in coastal Louisiana. Organization \& Environment, 20(3), 347-366. https://doi.org/10.1177/1086026607305739

Chamlee-Wright, E., \& Storr, V. H. (2009). "There's no place like New Orleans": Sense of place and community recovery in the Ninth Ward after Hurricane Katrina. Journal of Urban Affairs, 31(5), 615-634. https:// doi.org/10.1111/j.1467-9906.2009.00479.x

Clifford, J. (1996). Anthropology and/as travel. Etnofoor, 9(2), 5-15. https:// www.jstor.org/stable/25757889?seq=1

Consalvo, M. (2009). There is no magic circle. Games and Culture, 4(4), 408-417. https://doi.org/10.1177/1555412009343575

de Certeau, M. (1984). Walking in the city (S. Rendall, Trans.). In M. de Certeau (Ed.), The practice of everyday life (pp. 91-110). University of California Press. (Original work published in 1980)

DeSarbo, W. S., \& Madrigal, R. (2011). Examining the behavioral manifestations of fan avidity in sport marketing. Journal of Modelling in Management, 6, 79-99. https://doi.org/10.1108/17465661111112511

Deutsch, K., Yoon, S.-Y., \& Goulias, K. (2013). Modeling travel behavior and sense of place using a structural equation model. Journal of Transport Geography, 28, 155-163. https://doi.org/10.1016/j.jtrangeo.2012.12.001

Farokhmanesh, M. (2018, May 30). Two million people tuned to Bethesda's day-long stream of a toy. The Verge. https://www.theverge.com/2018/5/ 30/17408600/bethesda-fallout-76-twitch-stream

Griffith, C. (2018, October 11). WV, game developer partnering to promote the Mountain State. (Clarksburg, WV) Exponent-Telegram. https://www .wvnews.com/theet/news/wv-game-developer-partnering-to-promote-themountain-state/article_a4c36a5e-0cbe-5eb1-a6b9-99320e9f2750.html

Good, O. S. (2018a, May 30). Breaking down the Fallout 76 teaser trailer. Polygon. https://www.polygon.com/2018/5/30/17409604/fallout-76-trailerbreakdown

Good, O. S. (2018b, October 13). West Virginia is so ready for its Fallout 76 close-up. Polygon. https://www.polygon.com/2018/10/13/17969452/fallout76-west-virginia-locations

Gup, T. (1992, May 31). The ultimate Congressional hideaway. Washington Post. https://www.washingtonpost.com/wp-srv/local/daily/july/25/brier1 .htm?noredirect=on

Guttentag, D. A. (2010). Virtual reality: Applications and implications for tourism. Tourism Management, 31(5), 637-651. https://doi.org/10.1016/j .tourman.2009.07.003
Hernández, B., Carmen Hidalgo, M., Salazar-Laplace, M. E., \& Hess, S. (2007). Place attachment and place identity in natives and non-natives. Journal of Environmental Psychology, 27(4), 310-319. https://doi.org/10 .1016/j.jenvp.2007.06.003

Hemenover, S., \& Bowman, N. D. (2018). Video games, emotion, and emotion regulation: Expanding the scope. Annals of the International Communication Association, 42(2), 125-143. https://doi.org/10.1080/ 23808985.2018.1442239

Hess, J. J., Malilay, J. N., \& Parkinson, A. J. (2008). Climate Change. American Journal of Preventive Medicine, 35(5), 468-478. https://doi.org/ 10.1016/j.amepre.2008.08.024

Kohlbacher, J., Reeger, U., \& Schnell, P. (2015). Place attachment and social ties-Migrants and natives in three urban settings in Vienna. Population Space and Place, 21(5), 446-462. https://doi.org/10.1002/ psp. 1923

Kuchera, B. (2018, June 10). Tracking the real-world locations of Fallout 76 hints at a massive game. Polygon. https://www.polygon.com/2018/6/ 10/17447340/fallout-76-locations-west-virginia-real-world

Kteily, N. S., Hodson, G., Dhont, K., \& Ho, A. K. (2019). Predisposed to prejudice but responsive to intergroup contact? Testing the unique benefits of intergroup contact across different types of individual differences. Group Processes \& Intergroup Relations, 22(1), 3-25. https://doi.org/ $10.1177 / 1368430217716750$

Lentini, L., \& Decortis, F. (2010). Spaces and places: When interacting with and in physical space becomes a meaningful experience. Personal and Ubiquitous Computing, 14, 407-415. https://doi.org/10.1007/s00779-009-0267-y

Lombard, M., \& Ditton, T. (1997). At the heart of it all: The concept of presence. Journal of Computer-Mediated Communication, 3(2). https://doi.org/10 .1111/j.1083-6101.1997.tb00072.x

Massey, C. (2007). Appalachian stereotypes: Cultural history, gender, and sexual rhetoric. Journal of Appalachian Studies, 13(1/2), 124-136.

Nadler, A., Harpaz-Gorodeisky, G., \& Ben-David, Y. (2009). Defensive helping: Threat to group identity, ingroup identification, status stability, and common group identity as determinants of intergroup help-giving. Journal of Personality and Social Psychology, 97(5), 823-834. https:// doi.org/10.1037/a0015968

Nelson, P. (1970). Information and consumer behavior. Journal of Political Economy, 78(2), 311-329. https://doi.org/10.1086/259630

Oliver, M. B., Bowman, N. D., Woolley, J. K., Rogers, R., Sherrick, B., \& Chung, M.-Y. (2016). Video games as meaningful entertainment experiences. Psychology of Popular Media Culture, 5(4), 390-405. https://doi.org/10.1037/ppm0000066

Oliver, M. B., \& Raney, A. A. (2011). Entertainment as pleasurable and meaningful: Identifying hedonic and eudaimonic motivations for entertainment consumption. Journal of Communication, 61(5), 984-1004. https://doi.org/10.1111/j.1460-2466.2011.01585.x

Park, L. (2018). The varieties of place-based education. In R. Lansiquot \& S. MacDonald (Eds.), Interdisciplinary place-based learning in urban education (pp. 17-38). Palgrave Macmillan. https://doi.org/10.1007/978-3319-66014-1_2

Possler, D., Klimmt, C., \& Raney, A. A. (2018). Gaming is awesome! A theoretical model on cognitive demands and the elicitation of awe during video game play. In N. D. Bowman (Ed.), Video games: A medium that demands our attention (pp. 74-91). Routledge. https://doi.org/10.4324/ 9781351235266-5

Reinecke, L. (2009). Games and recovery. Journal of Media Psychology: Theories, Methods, and Applications, 21, 126-142. https://doi.org/10 .1027/1864-1105.21.3.126

Relph, E. (1976). Place and placelessness. Pion.

Rizzo, A., Reger, G., Gahm, G., Difede, J., \& Rothbaum, B. O. (2009). Virtual reality exposure therapy for combat-related PTSD. In P. J. Shiromani, T. M. Keane, \& J. E. LeDoux (Eds.), Post-traumatic stress disorder: Basic science and clinical practice (pp. 375-399). Humana Press. https://doi.org/10.1007/978-1-60327-329-9_18 
Statistica. (2019). Sales revenue generated by selected game titles within opening week worldwide as of March 2016 (in million U.S. dollars). https://www.statista.com/statistics/515562/selected-games-revenue-openingweek/

Swart, H., Hewstone, M., Christ, O., \& Voci, A. (2011). Affective mediators of intergroup contact: A three-wave longitudinal study in South Africa. Journal of Personality and Social Psychology, 101, 1221-1238. https:// doi.org/10.1037/a0024450

Tajfel, H., \& Turner, J. C. (1986). The social identity theory of intergroup behavior. In S. Worchel \& W. G. Austin (Eds.), Psychology of intergroup relations (pp. 7-24). Nelson Hall.

Tamborini, R., \& Bowman, N. D. (2010). Presence in video games. In C. Bracken \& P. Skalski (Eds.), Immersed in media (pp. 87-109). Routledge.

Tuan, Y.-F. (1974). Topophilia: A study of environmental perception, attitudes, and values. Prentice-Hall.

Tuan, Y.-F. (1975). Place: An experiential perspective. Geographical Review, 65(2), 151-165. https://doi.org/10.2307/213970

Tuan, Y.-F. (1979). Space and place: Humanistic perspective. In S. Gale \& G. Olsson (Eds.), Philosophy of Geography (pp. 387-427). Springer Netherlands. https://www.springer.com/gp/book/9789027709486

Turner, P., \& Turner, S. (2006). Place, sense of place, and presence. Presence (Cambridge, Mass.), 15(2), 204-217. https://doi.org/10.1162/pres.2006 .15.2.204

Twigger-Ross, C. L., \& Uzzell, D. L. (1996). Place and identity processes. Journal of Environmental Psychology, 16(3), 205-220.

Ubisoft. (2019). If Washington D.C. falls, humanity falls. https://tomclancythedivision.ubisoft.com/game/en-gb/the-division-2/story

Valiquette, C., \& McNamara, T. P. (2007). Different mental representations for place recognition and goal localization. Psychonomic Bulletin \& Review, 14, 676-680. https://doi.org/10.3758/BF03196820
Walker, P. (1999). From community presence to sense of place: Community experiences of adults with developmental disabilities. Journal of the Association for Persons with Severe Handicaps, 24(1), 23-32. https:// doi.org/10.2511/rpsd.24.1.23

Wen, Y., \& Looi, C.-K. (2019). Review of augmented reality in education: Situated learning with digital and non-digital resources. In P. Díaz, A. Ioannou, K. Bhagat, \& J. Spector (Eds.), Learning in a digital world (pp. 179-193). Springer. https://doi.org/10.1007/978-981-13-8265-9_9

White, N. R., \& White, P. B. (2004). Travel as transition. Annals of Tourism Research, 31(1), 200-218. https://doi.org/10.1016/j.annals.2003.10.005

Williamson, K., \& Roberts, J. (2010). Developing and sustaining a sense of place: The role of social information. Library \& Information Science Research, 32(4), 281-287. https://doi.org/10.1016/j.lisr.2010.07.012

Xu, F., Tian, F., Buhalis, D., \& Weber, J. (2013). Marketing tourism via electronic games: Understanding the motivation of tourist players [Paper presentation]. 5th International Conference on Games and Virtual Worlds for Serious Applications (VS-GAMES). https://doi.org/10.1109/VSGAMES.2013.6624235

Yee, N. (2006). Motivations for play in online games. CyberPsychology \& Behavior, 9(6), 772-775. https://doi.org/10.1089/cpb.2006.9.772

Zagalo, N., Göbel, S., Torres, A., Malkewitz, R., \& Branco, V. (2006). INSCAPE: Emotion expression and experience in an authoring environment. In S. Göbel, R. Malkewitz, \& I. Iurgel (Eds.), Technologies for interactive digital storytelling and entertainment (pp. 219-230). Springer. https://doi.org/10.1007/11944577_23

Received November 22, 2019

Revision received March 24, 2020

Accepted March 24, 2020 